Marquette University

e-Publications@Marquette

9-1994

\title{
Two Social Worlds: Social Correlates and Stability of Adolescent Status Groups
}

Stephen L. Franzoi

Marquette University, stephen.franzoi@marquette.edu

Mark H. Davis

Kristin A. Vasquez-Suson

Follow this and additional works at: https://epublications.marquette.edu/psych_fac

Part of the Psychology Commons

\section{Recommended Citation}

Franzoi, Stephen L.; Davis, Mark H.; and Vasquez-Suson, Kristin A., "Two Social Worlds: Social Correlates and Stability of Adolescent Status Groups" (1994). Psychology Faculty Research and Publications. 381. https://epublications.marquette.edu/psych_fac/381 


\title{
Marquette University
}

\section{e-Publications@Marquette}

\section{Faculty Research and Publications/College of}

This paper is NOT THE PUBLISHED VERSION; but the author's final, peer-reviewed manuscript. The published version may be accessed by following the link in the citation below.

Journal of Personality and Social Psychology, Vol. 67, No. 3 (September 1994): 462-473. DOI. This article is (C) American Psychological Association and permission has been granted for this version to appear in e-Publications@Marquette. American Psychological Association does not grant permission for this article to be further copied/distributed or hosted elsewhere without the express permission from American Psychological Association.

\section{Two Social Worlds: Social Correlates and Stability of Adolescent Status Groups}

\author{
Stephen L. Franzoi \\ Department of Psychology, Marquette University \\ Mark H. Davis \\ Behavioral Sciences, Eckerd College \\ Kristin A. Vasquez-Suson \\ Department of Psychology, Marquette University
}

\section{Acknowledgement}

We thank Richard Debelak for his help in scheduling our data collection. Resources for data collection were partially supplied by funds provided by the Post-Doctoral Program in Social Psychology (PHS T32 MH 14588-05) and the Post-Doctoral Program in Measurement (PHS T32 15798-02) at Indiana University and by a grant from the National Institute of Mental Health Small Grants Program (1 R03 MH 38989-01). 


\section{Introduction}

Social and personality psychologists in recent years have devoted increasing attention to what might be termed the individual's social ecology - that is, the nature of the social environment inhabited by that person. One example of such a focus is the research on loneliness that has identified characteristics of the social environment that contribute to or inhibit subjective feelings of isolation from others (e.g., Jones, Carpenter, \& Quintana, 1985; Schultz \& Moore, 1984). Similarly, investigators focusing on the topic of social support have often been interested in identifying the characteristics of the individual's social world that contribute to effective functioning and that provide protection from life's many stressors (e.g., Evans, Palsane, Lepore, \& Martin, 1989; Wills, 1991). An important assumption underlying all such work is that stable features of one's social worldincluding its size, complexity, density, and the provisions it affords-have meaningful influences on individual well-being.

Contemporary developmental psychologists have also been interested in the individual's social ecology but have sometimes used-with considerable success - an investigative approach quite different from that traditionally used by their social-personality colleagues. This approach focuses on the social reputation of the individual, and in particular on five different social status categories resulting from that reputation, that are thought to exist in school and preschool populations: what have come to be known as popular, controversial, average, neglected, and rejected children (e.g., Coie, Dodge, \& Coppotelli, 1982; Newcomb \& Bukowski, 1983). With this approach, status categories are generally assigned on the basis of a peer nomination process in which members of a group nominate other group members whom they like and whom they dislike. Popular individuals are those who receive many positive nominations and few negative ones, rejected individuals receive many negative and few positive nominations, controversial individuals receive many nominations of both types, and neglected individuals receive few of either type. Average individuals are usually defined as those who receive intermediate numbers of positive and negative nominations. Some versions of these categorization schemes typically assign $50 \%$ to $70 \%$ of the full sample to a category, with the rest receiving no classification (e.g., Coie et al., 1982); other versions classify all members of a population, typically by considerably expanding the size of the average category (Terry \& Coie, 1991). The general pattern that has emerged from this research is fairly easy to summarize. High-status (i.e., better liked) children tend to be more helpful, considerate, socially competent, and likely to follow rules (Coie, Dodge, \& Kupersmidt, 1990; Dodge, 1983). In contrast, lower status (less liked) children are usually more disruptive, aggressive, inappropriate, and hyperactive (Coie et al., 1990).

The real value of these classification schemes, however, has not come from comparing high- and low-status children in general, but from distinguishing between different types of popular and unpopular individuals. For example, a recent meta-analytic review of over 40 studies using this classification scheme (Newcomb, Bukowski, \& Pattee, 1993) indicates clear differences between the two low-status groups. Rejected children tend to be more aggressive, more withdrawn, less sociable, and less cognitively skilled than average children; in contrast, neglected children, despite being a low-status group characterized by extremely low social visibility, display this pattern much more weakly and are in fact not that different from the average child. This finding suggests that the truly toxic kind of unpopularity results from being actively rejected, rather than simply neglected, by one's peers. With regard to the two higher status categories, popular children are more sociable, less aggressive, and less withdrawn than average children and display a wealth of positive traits and social actions that result in enjoyable, shared social interaction. In contrast, controversial children display a combination of features characteristic of both rejected and popular children-heightened levels of aggression that even exceed those of the rejected group, coupled with heightened levels of sociability similar to those of popular children. This unusual mix of elements typically makes this a relatively small sociometric group. 


\section{Peer Status Among Adolescents}

In keeping with its origins in developmental psychology, the overwhelming emphasis of this research has been on the social status of relatively young children. Coie et al. (1990), in their review of research on the social behavior of rejected children, identified only 6 studies conducted with any sample older than seventh grade, compared with over 30 studies using younger groups. One consequence of this is that a somewhat restricted range of dependent variables has been examined-typically ratings of subjects by peers, adults, and teachers (e.g., Coie et al., 1982; Coie \& Dodge, 1988; French \& Waas, 1985; Newcomb \& Bukowski, 1983) or direct observation of social behavior (e.g., Dodge, Coie, \& Brakke, 1982; Ladd, 1983). Less attention has been paid to such issues as the number and quality of friendships, degree of social interaction, perceptions of the social world, and social feeling states-constructs that are quite frequently examined by social-personality psychologists in their investigations of adult samples. Whereas questions regarding these issues may be somewhat difficult to address with younger children because of limitations in their self-report ability, little such difficulty exists with older children. As a result, there is an opportunity, as yet unexploited, to examine the social ecology of older adolescents in a novel way, that is, by examining the correlates of their social status categories. That is the purpose of the present investigation.

The coupling of a theoretical-methodological approach widely used in the study of younger children with a set of substantive concerns more commonly associated with young adults is useful in two related ways. First, examining social status among older adolescents will help provide a more complete description of how status differences manifest themselves with increasing age. To state the obvious, adolescents are very different from grade-schoolers. Because they differ so dramatically in cognitive, emotional, and social sophistication, it seems likely that the behavior patterns that distinguish status categories in high school will be different from those found in grade school. For example, aggressive behavior is quite common among preschool and elementary populations, and higher and lower status children have frequently been found to differ substantially in their levels of overtly disruptive and aggressive behavior (Coie et al., 1982; Dodge, 1983). However, because the frequency of overt aggression declines markedly from preschool to high school, it seems unlikely that aggressive-disruptive behavior will remain as central a part of the behavioral profile of unpopular adolescents (Coie et al., 1990). Thus, it remains to be seen-in the relative absence of aggressive behavior-which individual characteristics may best differentiate high- and low-status groups during high school. One possibility suggested by previous work is that competence-especially academic and athletic-may become a more potent determinant of popularity with increasing age (Coie et al., 1990).

Thus, the first benefit of extending the social status approach to older populations is that it allows a consideration of whether the same, or different, variables distinguish the status categories at older ages. The second benefit is that it may provide a new way for social-personality psychologists to conceptualize the social worlds of young adults-namely, in terms of the specific social reputation of the individual. In particular, social status categories offer a new and potentially useful way to think about how the social worlds of adults may be organized. Because this system has proved quite useful in understanding the social environment of young children, it may prove similarly helpful in understanding the social experiences of those who are somewhere on the road between childhood and adulthood.

A final reason for studying social status among adolescents is that among younger children there is an apparent lack of temporal stability in these five social categories (Bukowski \& Newcomb, 1984; Terry \& Coie, 1991). The overall stabilities of the major classification schemes, assessed over a 1-year period, were reported by Terry and Coie (1991) as ranging from .15 to .18 (kappa statistic); over a 2-year period these values were even lower. Although there was some slight indication that stability might increase with age, the overall level of temporal stability must be characterized as, at best, unimpressive. With such high levels of change in status occurring, it is a decidedly open question as to whether the rejected, or neglected, or controversial groups in adolescence are made up of the same individuals - or even the same kind of individuals-as they are at earlier ages. 


\section{The Present Study}

With these considerations in mind, the present investigation focused on correlates of social status within a small midwestern high school, with a particular emphasis on the nature of the participants' social worlds. Instead of simply assessing how adolescents act or are seen by others, we hoped to discover something about the structure of the subjects' social environment and how they see themselves within it. To do so, we queried respondents, through use of a survey questionnaire, with regard to the following issues: friendships and activities (e.g., number of friends and close friends and frequency of social activity), disclosure and conflict (level of reported self-disclosure and degree of physical and verbal conflict), social feelings (e.g., loneliness and selfesteem), self-perceptions (e.g., self-perceived popularity and attractiveness), and competence (e.g., athletic and academic). In addition, we used the high school yearbook to derive several other measures, including physical attractiveness, social participation in clubs, peer recognition as represented by holding school offices and receiving social honors, and involvement with athletics. Finally, to evaluate the stability over time of status categories during high school, and to examine the robustness of any significant findings, we returned to the high school approximately 1 year later and collected exactly the same data.

\section{Method}

\section{Subjects and Overview}

In the spring of 1983 and 1984, identical survey questionnaires were administered to students enrolled in a high school in a small city (population approximately 8,000 ) in Michigan's upper peninsula. Parental permission was obtained for all students who were administered the survey, and questionnaires were completed by the students in the classroom during the normal 55-min periods. Four hundred eight students (209 boys and 199 girls) participated in the first year, and 404 (205 boys and 199 girls) participated in the second year. Sixty percent of the Year 2 subjects had also participated in Year 1. Although the retention rate from Year 1 to Year 2 may appear low, it is because roughly a quarter of the sample-the 1983 seniors-graduated from the high school later that spring. Of the 307 participants in Year 1 who were not seniors, and who therefore could return the following year, 257 in fact did so, producing a retention rate of $84 \%$. The remaining $16 \%$ were lost due to absences, transfers to other schools, and in some cases missing data in the Year 2 survey administration.

\section{Materials}

The survey questionnaire included items covering the following seven topics:

- Background. Respondents were asked three questions regarding their family background: number of children in the family, family income, and whether one, both, or neither of the biological parents lived at home (intact family).

- Individual characteristics. Two individual characteristics were assessed. As a rough measure of school achievement, each respondent was asked to report the kind of grades "you usually get: $1=$ mostly Ds, 2 $=$ mostly $C s, 3=$ mostly $B s$, and $4=$ mostly $A s . "$ In addition, the high school yearbook for the year in which data were collected was used to generate ratings of physical attractiveness for each participant. This physical attractiveness measure was obtained by having three male and three female judges evaluate the students' black-and-white yearbook photos. Evaluations were based on a 5-point Likert scale ranging from 1 (very unattractive) to 5 (very attractive). Judges' attractiveness ratings were correlated between the range of .58 and .62. Each student's physical attractiveness measure was based on the average of the six judges' evaluations $(\alpha=.90) .2$

- Friends and activities. Five variables assessed respondents' perceptions of quantitative aspects of their social worlds. The friends variable asked respondents to indicate "the number of your relationships with other kids" using one of four response options: "I have practically no friends," "I have fewer friends than most others my age," "I have as many friends as most others my age," and "I have more friends than most others my age." The close friends variable asked for a similar estimate of the "number of your really close friends" by choosing one of three response options: "I have no close friends," "I have one 
close friend," and "I have more than one close friend." Three items asked for estimates of different types of social activity. The dates items asked respondents to indicate "how often do you go out on dates with members of the opposite sex?"; the platonic activities item asked for an estimate of "how often do you go out and do things (not dates) with members of the opposite sex?"; and the same-sex activities item asked for an estimate of "how often do you go out and do things with members of the same sex?" Respondents answered each of these three questions by choosing one of four options: I never go out, I go out less than most others my age, I go out about as much as most others my age, and I go out more than most others my age.

- Disclosure and conflict. Four variables assessed the qualitative nature of respondents' social relationships. Same-sex disclosure and opposite-sex disclosure were measured by means of items taken from Miller, Berg, and Archer's (1983) Self-Disclosure Index. Respondents were asked to indicate separately the degree to which they discussed-with same-sex friends and with opposite-sex friendsthe following matters: "what is important to me in life," "what I like and dislike about myself," "my worst fears," and "things I have done which I feel guilty about." Responses were made on 5-point scales ranging from discuss not at all to discuss fully and completely. The internal reliability for the summed same-sex self-disclosure measure was .86 and for the opposite-sex self-disclosure measure, .87. Two measures of conflict within social relationships were included. The fights variable asked respondents to indicate how many "angry fights (fistfights, kicking, biting, hairpulling)" they had during the past 2 years with nonfamily members. The arguments variable asked for a similar estimate with regard to "angry arguments (repeated name calling, taunting, angry words)." For both variables the response options were $1=$ no fights (arguments), $2=1$ or $2,3=$ less than $5,4=$ between 5 and 10 , and $5=$ more than 10 .

- Social feelings. Three measures assessed social feeling states of the respondents. The satisfaction variable was a one-item measure requiring the subjects to indicate their degree of satisfaction with their friendships using one of four options: extremely satisfied, satisfied, not very satisfied, and not satisfied at all. Loneliness was assessed with the UCLA Loneliness Scale (Russell, Peplau, \& Cutrona, 1980); internal reliability in the present sample was .88. Self-esteem was assessed with Rosenberg's (1965) 10item Self-Esteem Scale ( $\alpha=.86)$.

- Self-perceptions. Three variables explicitly asked respondents to estimate the way in which they were viewed by others. The male popularity variable asked subjects to estimate "how well-liked are you by the male students here ... that is, how popular are you?" The female popularity variable asked for a similar estimate of popularity with "the female students here." For both variables the response options were not popular at all, a little less popular than most, as popular as most, a little more popular than most, and much more popular than most. The perceived attractiveness variable asked respondents to "compare your physical attractiveness ... with others of your age here." The response options were considerably more attractive than most, slightly more attractive than most, about the same as most, slightly less attractive than most, and considerably less attractive than most.

- Yearbook variables. Four measures of social involvement and activity were derived from information contained in the school yearbooks in the two testing years. Club membership was obtained by counting the number of different clubs (e.g., French Club, Band, and Drama Club) to which the student belonged. Sports participation was obtained by counting the number of different teams (e.g., boys' football and boys' and girls' basketball and track) of which the student was a member. Social honors were defined as the number of times students were singled out by fellow students to serve a special role in an organized social gathering (e.g., being voted on the Prom "court"). Finally, offices held was defined as the number of times students served as officers of student organizations (e.g., class officer or officer of a club).

- Data transformations. Initial inspection of the variable distributions revealed that in both years several variables were substantially skewed. Prior to analysis, then, square root transformations were carried out on these measures. The variables receiving this treatment were close friends, fights, satisfaction, clubs, offices, social honors, and sports. 


\section{Peer Nominations and Assignment to Status Groups}

Positive and negative peer nominations were elicited in both years by asking all respondents to list up to 10 other students in the high school who "you would be most likely to spend time with on a Saturday night" (PosNom) and up to 10 other students who "you would be least likely to spend time with on a Saturday night" (NegNom). The procedure used to then create the five status categories was modeled closely after the Coie et al. (1982) procedure, the most widely used status-assignment method and one that has been used in over two dozen studies (see Newcomb et al., 1993). We chose to assign status categories in this way primarily to maximize the comparability of this investigation with earlier work using younger samples. In addition, because our goal was not only to examine behavioral differences between the extreme groups but also to compare these extreme groups with a grouping of "average" adolescents, this method was useful in that it identifies a relatively homogeneous group of subjects whose number of positive and negative ties are near the population midpoint (Terry \& Coie, 1991). However, one consequence of using this selection procedure is that it also yields an "unclassifiable" set of subjects-approximately $30 \%$ to $50 \%$ of the total sample-who are on the boundary between the average group and the four extreme groups. The Coie et al. (1982) selection procedure that we adopted first calls for the raw positive (PosNom) and negative (NegNom) nomination scores to be standardized for male and female students separately (new variables = ZPosNom and ZNegNom). From these new variables, social preference ( $\mathrm{SP}=\mathrm{ZPosNom}-\mathrm{ZNegNom}$ ) and social impact ( $\mathrm{SI}=\mathrm{ZPosNom}+\mathrm{ZNegNom})$ scores were computed for each respondent. These SI and SP scores were then restandardized, and the resulting variables (ZSI and ZSP) were used to assign individuals to social status categories.

Respondents were assigned to the following status groups: popular (ZSP > 1.0; ZPosNom >0; ZNegNom < 0), rejected (ZSP <-1.0; ZPosNom < 0; ZNegNom >0), neglected (boys: ZSI <-.90 and PosNom < 2; girls: ZSI <-.90 and PosNom < 4), controversial (ZSI > .90; ZPosNom > 0; ZNegNom >0), and average $(-.50<\mathrm{ZSP}, \mathrm{ZSI}<.50)$. We altered the typical Coie et al. (1982) method in two ways to ensure reasonable cell sizes for some status categories. First, we slightly relaxed the cutoffs for ZSI from 1.0 to .9. Second, because so few students received absolutely no positive nominations (one of the usual requirements for membership in the neglected group), we allowed membership in this group with as many as one positive nomination (boys) and three positive nominations (girls).

\section{Results}

\section{Characteristics of the Year 1 and Year 2 Status Groups}

In Year 1, 124 of the 209 boys were classified (59\%), as were 105 of the 199 girls (53\%), figures roughly comparable with those found using this system with younger samples (e.g., Terry \& Coie, 1991). In Year 2, 114 of the 205 boys were classified (56\%), as were 106 of the 199 girls (53\%). These figures not only correspond closely to data from younger samples, they are also virtually identical to the Year 1 figures. The proportion of subjects

assigned to each category is also roughly comparable across years and when compared with previous work with younger samples. With the exception of the controversial male subjects in Year $1(n=9)$, all of the other statusgender cells contained at least 15 subjects.

\section{Analyses Involving the Year 1 and Year 2 Status Groups}

The first step in the analysis was to carry out a series of 5 (status) $\times 2$ (gender) multivariate analyses of variance (MANOVAs) for the Year 1 data on the seven variable clusters described earlier. Whenever a significant multivariate effect was discovered, follow-up univariate analyses were then carried out to determine the nature of the multivariate effect. Next, to determine the robustness of the status effects found in the Year 1 analyses, we carried out an identical series of MANOVAs on the seven Year 2 variable clusters using the Year 2 status categories; when significant, we also conducted univariate follow-ups. Table 1 displays the results of all the Year 1 and Year 2 MANOVAs. As this table reveals, significant multivariate status effects emerged for six of the seven Year 1 analyses and for all seven of the Year 2 analyses, indicating a quite substantial effect of social status on all the variable clusters; gender effects emerged less frequently, and Status $\times$ Gender interactions only twice. Of 
most theoretical interest, of course, are the univariate analyses carried out when significant multivariate status effects were found. We now turn our attention to these analyses.

Table I. Significant Multivariate Fs and Ps for Year I and Year 2 Analyses

\begin{tabular}{|l|l|l|l|l|l|l|}
\hline & Year 1 & & & Year 2 & & \\
\hline Mackground variables & & F & djs & F & $p$ & djs \\
\hline Status (S) & & & & 1.82 & .05 & 12,588 \\
\hline Gender (G) & & & & 2.99 & .05 & 3,194 \\
\hline Individual characteristics & & & & & & \\
\hline Status & 3.61 & .001 & 8,406 & 2.36 & .05 & 8,368 \\
\hline Friends/activities & & & & & & \\
\hline Status & 1.78 & .05 & 20,764 & 4.19 & .001 & 20,728 \\
\hline Disclosure/conflict & & & & & & \\
\hline Status & 3.02 & .001 & 16,780 & 1.50 & .10 & 16,728 \\
\hline Gender & 17.34 & .001 & 4,192 & 12.52 & .001 & 4,179 \\
\hline SXG & 1.87 & .05 & 16,780 & & & \\
\hline Social feelings & & & & & & \\
\hline Status & 2.08 & .05 & 12,576 & 3.41 & .001 & 12,549 \\
\hline Gender & 4.19 & .01 & 3,190 & 5.37 & .001 & 3,181 \\
\hline Self-perceptions & & & & & & \\
\hline Status & 2.17 & .05 & 12,600 & 4.79 & .001 & 12,576 \\
\hline SXG & 2.92 & .001 & 12,600 & & & \\
\hline Yearbook data & & & & & & \\
\hline Status & 5.74 & .001 & 16,876 & 4.05 & .001 & 16,840 \\
\hline Gender & 14.32 & .001 & 4,216 & 7.29 & .001 & 4,207 \\
\hline
\end{tabular}

\section{Background variables}

Univariate analyses in Year 2 (no significant multivariate effects emerged in Year 1) revealed significant status and gender effects only for income (both $F s>2.48$, both $p s<.05$ ); the rejected and neglected students reported lower parental incomes than the popular students, and male students claimed higher family incomes than female students.

Individual student characteristics

Univariate analyses at Year 1 revealed a significant status effect for the individual characteristic of physical attractiveness, $F(4,212)=5.67, p<.001$, and a marginal status effect for reported grades, $F(4,212)=2.01, p<$ .10. As Table 2 reveals, the popular and controversial groups were highest in attractiveness, followed by the average group, and then by the rejected and neglected groups. Similarly, the controversial and popular groups reported the highest grades, the rejected group the lowest, with the average and neglected groups in between. For Year 2, there was a significant status effect for self-reported grades, $F(4,182)=6.34, p<.001$; as Table 3 indicates, compared with the other four status groups, rejected individuals again reported significantly lower grades. In contrast with the first-year results, physical attractiveness was not significantly associated with status at Year $2(F<1)$.

Table 2. Means for Each Social Status Group on Variables for Which a Significant Univariate Status Effect was Found in Year 1 


\begin{tabular}{|l|l|l|l|l|l|}
\hline Measure & $\begin{array}{l}\text { Popular } \\
(\mathbf{n = 4 4 )}\end{array}$ & $\begin{array}{l}\text { Controversial } \\
(\mathbf{n = 2 9}\end{array}$ & $\begin{array}{l}\text { Rejected } \\
\mathbf{( n = 4 1 )}\end{array}$ & $\begin{array}{l}\text { Neglected } \\
\mathbf{( n = 3 3 )}\end{array}$ & $\begin{array}{l}\text { Average } \\
\text { (n= 82) }\end{array}$ \\
\hline Individual characteristics & $3.13_{\mathrm{ad}}$ & $3.22_{\mathrm{a}}$ & $2.64_{\mathrm{bc}}$ & $2.57_{\mathrm{b}}$ & $2.91_{\mathrm{cd}}$ \\
\hline Physical attractiveness & $2.80_{\mathrm{a}}$ & $2.93_{\mathrm{a}}$ & $2.38_{\mathrm{b}}$ & $2.71_{\mathrm{ab}}$ & $2.71_{\mathrm{ab}}$ \\
\hline Self-reported grades & $1.72_{\mathrm{a}}$ & $1.72_{\mathrm{a}}$ & $1.63_{\mathrm{b}}$ & $1.60_{\mathrm{b}}$ & $1.65_{\mathrm{b}}$ \\
\hline Friends/activities & $2.78_{\mathrm{a}}$ & $3.21_{\mathrm{b}}$ & $2.54_{\mathrm{a}}$ & $2.54_{\mathrm{a}}$ & $2.97_{\mathrm{b}}$ \\
\hline Close friends & $3.12_{\mathrm{a}}$ & $3.10_{\mathrm{a}}$ & $2.68_{\mathrm{bc}}$ & $2.62_{\mathrm{bc}}$ & $2.94_{\mathrm{ac}}$ \\
\hline Dates & $3.24_{\mathrm{a}}$ & $3.17_{\mathrm{a}}$ & $2.95_{\mathrm{ab}}$ & $2.72_{\mathrm{b}}$ & $3.06_{\mathrm{a}}$ \\
\hline Platonic activity & & & & & \\
\hline Same-sex activity & $13.9_{\mathrm{a}}$ & $15.7_{\mathrm{c}}$ & $12.4_{\mathrm{ab}}$ & $11.4_{\mathrm{b}}$ & $13.7_{\mathrm{a}}$ \\
\hline Disclosure/conflict & $12.2_{\mathrm{a}}$ & $14.3_{\mathrm{bc}}$ & $11.4_{\mathrm{a}}$ & $11.4_{\mathrm{a}}$ & $13.1_{\mathrm{ac}}$ \\
\hline Same-sex self-disclosure & $33.2_{\mathrm{a}}$ & $34.0_{\mathrm{a}}$ & $39.7_{\mathrm{b}}$ & $41.0_{\mathrm{b}}$ & $39.4_{\mathrm{b}}$ \\
\hline Opposite-sex self-disclosure & & & & & \\
\hline Social feelings & $3.23_{\mathrm{a}}$ & $3.22_{\mathrm{a}}$ & $2.61_{\mathrm{b}}$ & $2.55_{\mathrm{b}}$ & $3.00_{\mathrm{a}}$ \\
\hline Loneliness & $3.24_{\mathrm{a}}$ & $3.14_{\mathrm{a}}$ & $2.78_{\mathrm{b}}$ & $2.76_{\mathrm{b}}$ & $2.97_{\mathrm{ab}}$ \\
\hline Self-perceptions & & & & & \\
\hline Popularity with male students & $1.03_{\mathrm{a}}$ & $1.02_{\mathrm{a}}$ & $0.76_{\mathrm{ab}}$ & $0.48_{\mathrm{b}}$ & $0.81_{\mathrm{ab}}$ \\
\hline Popularity with female students & $0.24_{\mathrm{a}}$ & $0.67_{\mathrm{a}}$ & $0.06_{\mathrm{b}}$ & $0.10_{\mathrm{b}}$ & $0.06_{\mathrm{b}}$ \\
\hline Yearbook & $0.79_{\mathrm{a}}$ & $0.57_{\mathrm{abc}}$ & $0.30_{\mathrm{bc}}$ & $0.32_{\mathrm{b}}$ & $0.57_{\mathrm{a}}$ \\
\hline Clubs & & & & \\
\hline Social honors & & & & \\
\hline Athletic teams & & & & & \\
\hline
\end{tabular}

Note. All comparisons were made between, not within, status groups. Mean not sharing a common sub script significantly differ at $p<.05$.

Table 3. Means for Each Social Status Group on Variables for Which a Significant Univariate Status Effect was Found in Year

\begin{tabular}{|l|l|l|l|l|l|}
\hline Measure & $\begin{array}{l}\text { Popular } \\
\text { (n= 35) }\end{array}$ & $\begin{array}{l}\text { Controversial } \\
(\mathbf{n = 3 3}\end{array}$ & $\begin{array}{l}\text { Rejected } \\
\text { (n=34) }\end{array}$ & $\begin{array}{l}\text { Neglected } \\
\text { (n= 41) }\end{array}$ & $\begin{array}{l}\text { Average } \\
\text { (n= 79) }\end{array}$ \\
\hline Background & $3.49_{\mathrm{a}}$ & $3.03_{\mathrm{ab}}$ & $2.70_{\mathrm{bc}}$ & $2.67_{\mathrm{bd}}$ & $3.10_{\mathrm{acd}}$ \\
\hline Income & & & & & \\
\hline Individual characteristics & $2.86_{\mathrm{a}}$ & $2.74_{\mathrm{ac}}$ & $2.11_{\mathrm{b}}$ & $2.53_{\mathrm{c}}$ & $2.88_{\mathrm{a}}$ \\
\hline Self-reported grades & & & & & \\
\hline Friends/activities & $3.19_{\mathrm{ac}}$ & $3.44 \mathrm{~d}$ & $2.91_{\mathrm{bc}}$ & $2.74_{\mathrm{b}}$ & $3.20_{\mathrm{a}}$ \\
\hline Number of friends & $1.72_{\mathrm{a}}$ & $1.72 \mathrm{a}$ & $1.62_{\mathrm{bd}}$ & $1.53_{\mathrm{bc}}$ & $1.67_{\mathrm{d}}$ \\
\hline Close friends & $2.91_{\mathrm{a}}$ & $3.39_{\mathrm{c}}$ & $2.35_{\mathrm{b}}$ & $2.29_{\mathrm{b}}$ & $2.76_{\mathrm{a}}$ \\
\hline Dates & $3.09_{\mathrm{a}}$ & $3.42_{\mathrm{c}}$ & $2.59_{\mathrm{b}}$ & $2.36_{\mathrm{b}}$ & $3.07_{\mathrm{a}}$ \\
\hline Platonic activity & $3.13_{\mathrm{a}}$ & $3.42_{\mathrm{c}}$ & & & \\
\hline Same-sex activity & & & & & \\
\hline Disclosure/conflict & $12.03_{\mathrm{ab}}$ & $13.73_{\mathrm{a}}$ & $2.84_{\mathrm{a}}$ & $2.49_{\mathrm{b}}$ & $3.13_{\mathrm{a}}$ \\
\hline Opposite-sex self-disclosure & & & & & \\
\hline Social feelings & $32.50_{\mathrm{a}}$ & $32.16_{\mathrm{a}}$ & $39.21_{\mathrm{bd}}$ & $44.03_{\mathrm{bc}}$ & $37.09_{\mathrm{d}}$ \\
\hline Loneliness & & & & & \\
\hline Self-perceptions & $2.82_{\mathrm{a}}$ & $2.65_{\mathrm{a}}$ & $2.76_{\mathrm{a}}$ & $3.25_{\mathrm{b}}$ & $2.77_{\mathrm{a}}$ \\
\hline Physical attractiveness & & & & & \\
\hline
\end{tabular}




\begin{tabular}{|l|l|l|l|l|l|}
\hline Popularity with male students & $3.12_{\mathrm{a}}$ & $3.29_{\mathrm{a}}$ & $2.24_{\mathrm{b}}$ & $2.29_{\mathrm{b}}$ & $3.01_{\mathrm{a}}$ \\
\hline Popularity with female students & $3.18_{\mathrm{ab}}$ & $3.45_{\mathrm{b}}$ & $2.44_{\mathrm{c}}$ & $2.72_{\mathrm{c}}$ & $3.08_{\mathrm{a}}$ \\
\hline Yearbook & & & & & \\
\hline Clubs & $0.70_{\mathrm{a}}$ & $0.31_{\mathrm{b}}$ & $0.35_{\mathrm{bc}}$ & $0.32_{\mathrm{bc}}$ & $0.50_{\mathrm{abc}}$ \\
\hline Social honors & $0.25_{\mathrm{ad}}$ & $0.31_{\mathrm{a}}$ & $0.00_{\mathrm{b}}$ & $0.02_{\mathrm{bc}}$ & $0.08_{\mathrm{cd}}$ \\
\hline Athletic teams & $0.59_{\mathrm{a}}$ & $0.62_{\mathrm{a}}$ & $0.23_{\mathrm{b}}$ & $0.31_{\mathrm{bc}}$ & $0.46_{\mathrm{ac}}$ \\
\hline Offices & $0.31_{\mathrm{a}}$ & $0.06_{\mathrm{b}}$ & $0.03_{\mathrm{b}}$ & $0.02_{\mathrm{b}}$ & $0.09_{\mathrm{b}}$ \\
\hline
\end{tabular}

Note. All comparisons were made between, not within, status groups. Mean not sharing a common sub-script significantly differ at $p<.05$.

\section{Friends and activities}

Year 1 univariate analyses revealed significant status effects on four of the five variables assessing friendship patterns and social activities: number of close friends, number of dates, nonromantic activities with the opposite sex, and activities with same-sex friends (all Fs $>2.89$, all $p s<.05$ ). Table 2 reveals a fairly clear pattern: The popular and controversial groups reported more social activity than the rejected and neglected students. Moreover, the rejected and neglected students were highly similar to one another, never differing on any variable; the popular and controversial groups were also largely equivalent in social activities, differing only in that controversial students reported more dates.

Consistent with the Year 1 pattern, univariate analyses in Year 2 produced significant status effects on all five variables in the cluster: number of friends, number of close friends, number of dates, nonromantic activities with the opposite sex, and activities with same-sex friends (all $F s>6.59$, all $p s<.001$ ). As Table 3 reveals, the pattern paralleled that found in Year 1: generally similar, and lower, levels of social activity among the rejected and neglected students, with greater social activity among the popular and controversial groups.

\section{Disclosure and conflict}

Univariate analyses at Year 1 indicated significant status effects on self-disclosure to both same-sex and opposite-sex friends (both $F s>2.75$, both $p s<.05$ ). As Table 2 reveals, the general pattern noted thus far persisted: The rejected and neglected groups reported the lowest levels of disclosure to others, whereas the popular and controversial groups tended to report the highest. These Year 1 analyses also revealed significant gender effects on both self-disclosure variables and the reported number of physical fights (all Fs $>4.58$, all $p s<$ .05), with girls reporting fewer fights and greater disclosure than boys. Finally, the univariate analyses revealed one significant Status $\times$ Gender interaction: for self-reported fights, $F(4,195)=4.96, p<.001$. Although status had no association with fighting among girls $(F<1)$, there was a significant relation among boys, $F(4,108)=3.30$, $p<.05$, created by the greater number of fights reported by neglected male subjects.

Univariate analyses at Year 2 revealed a significant status effect for opposite-sex self-disclosure, $F(4,182)=2.55$, $p<.05$, with controversial students reporting more disclosure to members of the opposite sex. In addition, girls reported engaging in more same-sex self-disclosure, $F(4,182)=29.79, p<.001$, whereas boys reported engaging in more physical fights and arguments (both $F s>9.64$, both $p s<.01$ ).

\section{Social feelings}

Univariate analyses of the social feelings variables at Year 1 revealed a significant status effect for loneliness, $F(4,192)=4.41, p<.01$. As Table 2 reveals, the popular and controversial groups were significantly less lonely than the other three groups. Univariate analyses at Year 2 revealed a similar significant status effect for loneliness, $F(4,183)=8.82, p<.001$, with the popular and controversial students reporting the lowest levels of loneliness. In addition, girls at Year 2 reported somewhat lower self-esteem and satisfaction with their social relationships than did boys (both Fs $>4.94$, both $p s<.05$ ). 


\section{Self-perceptions}

Univariate analyses at Year 1 revealed a significant status effect for self-perceived male peer popularity, $F(4$, $200)=5.92, p<.001$, and a nearly significant effect for self-perceived female peer popularity, $F(4,200)=2.28, p$ $<.07$. As Table 2 reveals, the popular and controversial groups perceived themselves as more popular than the rejected and neglected groups, with the average group falling in between. The Year 1 univariate analyses also revealed one significant Status $\times$ Gender effect: for perceived physical attractiveness, $F(4,200)=2.64, p<.05$. This resulted from controversial and average male subjects perceiving themselves as more attractive, $F(4,108)=$ $3.42, p<.05$.

Univariate analyses at Year 2 revealed significant status effects for the two perceived popularity measures ( $F \mathrm{~s}>$ $8,58, p s<.001)$ and for perceived physical attractiveness, $F(4,192)=2.42, p<.05$. Similar to Year 1 findings, the popular and controversial groups perceived themselves to be more popular with male and female peers than did the other status groups. The neglected group members perceived themselves to be significantly less physically attractive than any other group.

\section{Yearbook variables}

Univariate analyses of the data derived from the yearbook at Year 1 revealed significant status effects for number of clubs, number of social honors, and participation in sports (all $F s>3.27$, all $p s<.05$ ). As can be seen in Table 2, the popular and controversial groups were generally higher on all three of these variables than the rejected and neglected groups, with the average group falling in between. Significant univariate effects of gender were found for the clubs, offices held, and sports participation variables (all $F s>11.14$, all $p s<.001$ ), with female students belonging to more clubs, holding more offices, and participating less in sports than male students.

Univariate analyses at Year 2 revealed significant status effects for all four yearbook variables: clubs, offices held, social honors, and participation in sports (all $F s>3.24$, all $p s<.05$ ). Generally consistent with the Year 1 data, the popular students displayed the greatest integration into school activities, and the rejected and neglected students displayed the least. Also similar to Year 1, significant univariate gender effects were found for clubs, offices held, and sports participation (all $F s>4.00$, all $p s<.05$ ), with female students belonging to more clubs, holding more offices, and participating in fewer sports than male students.

Overall, the results of these analyses indicate that the status effects were highly robust. Of the six variable clusters for which significant multivariate status effects had emerged in Year 1, five also displayed such effects in Year 2; only the disclosure-conflict cluster failed to do so, and in even this case the multivariate status effect approached significance $(\mathrm{p}<.10)$. Furthermore, of the 14 significant or marginally significant univariate status effects found in Year 1 (Table 2), 12 were also significant in Year 2 (Table 3); only physical attractiveness and same-sex disclosure failed to display a significant status effect in the second year. Thus, in broad overview it is clear that the status categories in this investigation were predictably and reliably associated with a variety of social feelings and behaviors. The fact that only $21 \%$ of the respondents receiving a status classification in Year 2 had received the same status in Year 1 further indicates that it is membership in the status group itself-and not simply the particular individuals involved-that accounts for the consistency of these effects.

\section{Post Hoc Contrasts Involving the Year 1 and Year 2 Status Groups}

An inspection of the significant univariate status effects displayed in $\underline{\text { Tables } 2}$ and $\underline{3}$ reveals a consistent pattern-popular and controversial students displaying consistently "better" levels of each variable than neglected and rejected students, with the average students falling roughly in between. In fact, in Year 1 the neglected and rejected groups never differed significantly from one another on any of the 14 variables displayed in Table 2, whereas the popular and controversial groups differed on 3. In Year 2, of the 16 variables appearing in $\underline{\text { Table } 3}$, the popular and controversial groups differed on 6; the rejected and neglected groups differed on 
only 3. To better understand the differences between high- and low-status students, we carried out a series of unplanned, exploratory contrasts pitting popular-controversial versus average versus neglected-rejected groups.

For each of the 14 variables in the Year 1 data, the contrast between the two extremes-popular-controversial and rejected-neglected students-was significant, with the popular-controversial students displaying greater attractiveness, more social activity, less loneliness, and so forth. The contrasts involving the intermediate average group displayed a more variable pattern. The average students significantly differed from the popularcontroversial students on 6 variables: They were less physically attractive, had fewer close friends, engaged in less same-sex self-disclosure, were more lonely, perceived themselves as less popular with male peers, and received fewer social honors. The average group differed from the neglected-rejected students on 8 variables: They were more physically attractive, dated more, had more opposite-sex and same-sex friends, engaged in more same-sex and opposite-sex self-disclosure, perceived themselves to be more popular with male students, and engaged in more sports activities.

In Year 2, a similar pattern was found. For every 1 of the 16 comparisons between the popular-controversial and the neglected-rejected groups, the difference was significant or marginally significant. Again, consistent with the Year 1 data, clear differences were also found between the average students and the lower status groupings. Indeed, in only two instances did the average group not differ from the neglected-rejected students (self-perceived attractiveness and membership in school clubs). As in Year 1, the average students more closely resembled the higher status students than the lower status ones. For 12 of the Year 2 comparisons, the average group did not differ significantly from the popular-controversial group; group members did, however, report fewer close friends, dates, social honors, and more loneliness. Thus, although the average group resembled the more popular students in many ways, some important differences remained.

\section{Stability of Social Status}

Stability of social status was assessed in two ways. First, we computed test-retest reliabilities on the four continuous variables from which the status groups were derived: number of positive and negative nominations and the social preference and social impact scores that were based on those nominations. The resulting correlation coefficients were based on data from all students who were subjects in both Year 1 and Year 2, including those who fell into the unclassified category. These analyses revealed a high degree of test-retest reliability for both the total number of positive nominations $(r=.66, p<.001)$ and negative nominations $(r=.72$, $p<.001)$ as well as for the social preference $(r=.75, p<.001)$ and social impact $(r=.62, p<.001)$ measures. Although these analyses indicated that the number of positive and negative nominations from peers during a 1year period was quite reliable, they did not assess the stability of the actual status categories. That is, to what degree do subjects retain their specific status classification over a 1-year period?

To fairly assess the stability of status classification, it was necessary to also include in these analyses subjects who were not classified in Year 1 or in Year 2. To do otherwise would artificially inflate stability estimates by eliminating from the analysis those subjects who went from classified status at Year 1 to unclassified status at Year 2 (cf. Coie \& Dodge, 1983). Thus, using a procedure similar to that of Terry and Coie (1991), we crosstabulated the status categories for Year 1 and Year 2, including the unclassifiable subjects, and then calculated Cohen's (1960) kappa coefficient ( $\mathrm{k}$ ) to determine the overall stability of the status categories. Following Landis and Koch (1977), kappa values less than .30 were judged to constitute only slight to fair stability, values between .30 and .60 were considered to indicate moderate stability, and kappa values exceeding .60 were indicative of excellent stability.

Of the 243 students who completed usable questionnaires in both testing years, 98 (40\%) retained their original social grouping ( $\mathrm{k}=.19, p<.05$ ), a low level of stability comparable with that found in studies of younger children (Bukowski \& Newcomb, 1984; Coie \& Dodge, 1983; Terry \& Coie, 1991). Previous investigations 
(Newcomb \& Bukowski, 1984; Terry \& Coie, 1991) have also reported stability coefficients after relaxing the restrictions for the average status category so that it includes the unclassified subjects. When we used these procedures and expanded our average group, 147 of the students (60\%) retained their original social grouping. The overall stability with this expanded average group increased to a moderate level of $.30, p<.05$, which is slightly higher than that found in the younger samples of Terry and Coie (average $k=.18$ ) using this expanded average range.

Just as important as the overall stability was the individual stability of the five status groups, particularly the rejected and neglected adolescents. As can be seen from Table 4, the stability of the five status groups varied considerably, from a kappa of .10 for the popular category to .49 for the neglected. The unclassifiable students actually exhibited the highest stability of all, with $44 \%$ remaining unclassifiable from one year to the next $(\mathrm{k}=$ $.58, p<.05)$. In two cases the level of stability in this sample was noticeably greater than that found with younger samples: The average category, in which our kappa of .21 was larger than the mean value of .05 reported by Terry and Coie (1991), and the neglected category (.49 vs. .05). In two other categories our degree of stability was lower than that of the younger samples: the popular (.10 vs. .47) and the rejected (.20 vs. .35) categories. The stability of our controversial group (.16) was quite comparable with the mean stability of younger samples (.13) reported by Terry and Coie (1991). One feature of Table 4 is worthy of special note; those students who received a higher (popular-controversial) or lower (rejected-neglected) status categorization at Year 1 did not move very far from that status in Year 2. That is, although a large number of students failed to retain their particular status category, virtually none of the movement was random. Only 1 of the 87 students classified in a high- or low-status group at Year 1 moved into the other status group at Year 2.

Table 4. Stability of Status Classification Over the 1-Year Time Interval

\begin{tabular}{|l|l|l|l|l|l|l|}
\hline & $\begin{array}{l}\text { Year 1 } \\
\text { classification }\end{array}$ & Controversial & Rejected & Neglected & Average & $\begin{array}{l}\text { No } \\
\text { classification }\end{array}$ \\
\hline $\begin{array}{l}\text { Year 2 } \\
\text { classification }\end{array}$ & 6 & 1 & 0 & 0 & 3 & 7 \\
\hline Popular & 6 & 6 & 0 & 0 & 7 & 6 \\
\hline Controversial & 0 & 0 & 8 & 2 & 2 & 4 \\
\hline Rejected & 0 & 1 & 1 & 11 & 2 & 9 \\
\hline Neglected & 1 & 4 & 1 & 1 & 19 & 26 \\
\hline Average & 11 & 8 & 14 & 5 & 23 & 48 \\
\hline No classification & .10 & .16 & $.20^{*}$ & $.49 *$ & $.21^{*}$ & $.58^{*}$ \\
\hline k & & & & & & \\
\hline
\end{tabular}

${ }^{*} p<.05$.

\section{Discussion}

The results of this investigation provide generally strong support for the view that differences in social status are associated with important differences in the quality of the social environment available to high school students. The more popular students differed from less popular students on a number of self-report dimensions as well as on several independently derived measures of social participation. In particular, higher status students were more involved in school activities such as clubs and were more likely to receive social honors from their schoolmates. They reported having more close friends, engaging more frequently in activities with their friends, and sharing more intimate self-disclosure with them as well. They tended to accurately perceive their greater level of popularity and reported less loneliness than did the lower status students. In short, popular and controversial adolescents appear to live in a somewhat richer, more varied, and rewarding social environment than do the lower status rejected and neglected students.

Moreover, these findings were generally quite robust; all but 2 of the 14 significant univariate status effects that emerged at Year 1 were also significant at Year 2. This is especially impresive given the fact that only $21 \%$ of the 
participants receiving a status classification in Year 2 had received the same classification in Year 1 . Thus, the replicability of these findings does not seem to be due simply to the fact that the same individuals were being examined a second time. Given the generally reliable nature of these findings, it is probably wise not to attribute too much meaning to the two findings that did not replicate. However, with regard to the failure to replicate the Year 1 effect of status on physical attractiveness, it might be noted that the relationship between attractiveness and peer acceptance probably becomes more complex with age and thus perhaps less reliable. Krebs and Adinolfi (1975), for example, found that the college freshmen (of both sexes) who were most rejected by their same-sex dorm mates were also rated by independent judges as the most attractive. It may simply be that the complexity of the forces involved at this age (e.g., jealousy and social comparison) might render the statusattractiveness association somewhat volatile.

Whereas the social environments of the high- and low-status groups were markedly different on a number of dimensions related directly to peer relations, social status was not significantly related to all variables under investigation. For example, only one background variable-family income-was ever associated with status, and this effect emerged only in Year 2. More important, neither of the two measures of interpersonal conflict used in this study-self-reported fights and angry arguments-displayed a reliable association with status category. This finding contrasts sharply with the typical pattern found with younger samples, but is entirely consistent with the view, offered by Coie et al. (1990), that with increasing age aggressive behavior becomes a relatively less important factor in social status, whereas athletic and academic competence become more important.

In fact, both academic (reported grades) and athletic (sports participation) competence consistently displayed status effects in this investigation. In each case, rejected students were the least competent in these areas, and the popular-controversial students were the most competent. The differences between the popular and rejected groups were always significant on these variables, and the difference between the controversial and rejected groups almost always so. Thus, this pattern suggests that with increasing age the higher and lower status groups may be differentiated more on the basis of their performance in valued areas of school life rather than on overt antisocial behavior such as outright aggression.

\section{Rejected Versus Neglected Status}

One of the most important contributions of the recent developmental work on peer status has been the distinguishing of two different types of unpopular children, the rejected and neglected. A number of investigations have produced evidence supporting the usefulness of distinguishing these groups (e.g., Dodge, 1983; Kennedy, 1990). It was somewhat surprising, then, to find in this investigation almost no meaningful differences between these two groups. In fact, the only variable in this investigation that displayed any reliable tendency to differentiate the rejected and neglected groups was self-reported grades. Why might this be?

As previously mentioned, one likely possibility has to do with the changes in social behavior that occur between elementary and high school. With high levels of aggressive and disruptive behavior common at early ages, the occurrence of such behavior seems to play a substantial role in the assignment of rejected status. The most aggressive and disruptive children tend to be rejected, whereas neglected children, by virtue of their lower levels of aggression, generally avoid outright rejection. However, with the decline in aggressive behavior that occurs with age, what comes to differentiate the rejected from the neglected? One possibility is that indices of competence become more important, and the differences in reported grades between the rejected group and the other status categories support this view. Another possibility is that with age social withdrawal comes to be a more potent cause of rejection. Rubin, LeMare, and Lollis (1990) have argued that by late elementary school it is a pattern of isolation and withdrawal from others - rather than aggressive behavior-that is most strongly associated with rejection by peers. If, as seems plausible, this pattern continues into middle school and beyond, the results of the present study can be viewed as consistent with this argument. No significant status main effects emerged for either the fights or arguments variables in this study, but the lower status categories-both 
rejected and neglected-repeatedly displayed diminished levels of social integration and activity consistent with the withdrawal hypothesis.

It is also possible, of course, that social withdrawal is the result of peer rejection rather than its cause (Coie et al., 1990) -that as a result of chronic rejection, some individuals increasingly disengage themselves from social interaction. In either case, however, whether withdrawal leads to rejection or vice versa, it may be reasonable to expect the rejected and neglected groups to appear more similar-at least on measures of social activity-by mid- to late adolescence. The reason for this is that aggressive behavior, of the kind common in younger children, by its nature cannot be easily ignored or neglected by others; because it constitutes a direct threat to well-being, an active rejection of the aggressor is required. Social withdrawal, however, can be ignored, and thus the treatment accorded to the adolescent rejected group may come to increasingly resemble neglect; in short, rejection and neglect may come to largely feel the same during adolescence. At least one other study has reported data consistent with this view; Frentz, Gresham, and Elliott (1991) found that behavioral problems (e.g., attention problems and anxiety and withdrawal) reported by neglected middle and high school students were most similar to those reported by rejected students.

\section{Popular Versus Controversial Status}

Although the popular and controversial students were also more alike than different in this investigation, there were some differences, and these differences seem quite compatible with earlier findings regarding the behavioral characteristics of controversial children. Coie et al. (1990) have described the composite picture of controversial children that has emerged in the following way:

Controversial children are the most socially active of all children. They are often engaged in active interaction with peers and are rarely observed in solitary activity. They talk frequently with peers and adults and make the peer group laugh with their humor. (p. 52)

Consistent with this view, we found that controversial adolescents reported generally higher levels of selfdisclosure to both same-sex and opposite-sex peers than did their popular counterparts. In fact, for both measures the controversial group reported higher levels of self-disclosure than any other group. In addition, the controversial students in the present investigation also reported having more dates than the popular group, which is also consistent with a view of this group as more socially active than the other high-status group. Thus, the differences between the popular and controversial groups were most apparent on the measures that primarily tap contact with the opposite sex. What this may suggest is that in a sample of this age the natural extraversion and high social activity level of the controversial children may begin to manifest at least in part by greater and earlier activity in the romantic realm. It seems plausible, moreover, that engaging in a greater-thanusual amount of opposite-sex contact could also have the effect, within a closed system such as a small high school, of further reinforcing one's controversial status.

In fact, this may help us to understand another interesting feature of these results: On all three of the Year 1 opposite-sex measures (dates, platonic activities, and opposite-sex disclosure) the average group did not differ from the controversial group. In fact, it was the average group that was most similar to the controversial group on both the dates and opposite-sex disclosure variables. It appears from this pattern that the popular group might actually lag behind the average and controversial students with regard to opposite-sex activity and that this might in fact contribute to their popularity. One way to view the popular group at this age is as a group of individuals still more oriented toward group activities with peers, perhaps especially same-sex peers. More active involvement in the romantic realm - to the extent that it limits the time available to be with other peersmay reduce the positive nominations received. Thus, the failure to date as much as the controversial or average group may actually contribute to higher peer status. This interpretation must be tempered, however, by the fact that this pattern was not so strongly apparent in Year 2-of the three opposite-sex variables, only opposite-sex disclosure displayed a similar pattern of means. Future investigations might therefore fruitfully explore this possibility. More generally, of course, the role of dating in the acquisition and maintenance of social status is an almost completely unexamined area. 


\section{Temporal Stability of the Status Groups}

Taken as a whole, what do these data suggest about the stability of adolescent social status? On the basis of the analysis using the expanded average group where $\mathrm{k}=.30$, an argument could be made that adolescents' overall status stability is slightly higher than that found in younger children (average $\mathrm{k}=.18$ ). Such an argument, however, cannot ignore the fact that the overall stability of the adolescent status groups was still quite modest. It appears that even in adolescence there is a good deal of year-to-year variation in a person's social status.

Beyond this general statement, what do the individual analyses of the four extreme groups suggest about status stability? The neglected adolescents displayed by far the most stable social status, with a stability coefficient of .49; $58 \%$ of the neglected students retained their status from Year 1 to Year 2, compared with an average retention rate of $29 \%$ for the other three extreme groups. This relatively high stability also stands in sharp contrast with that found in younger samples, where the temporal stability of neglected children has ranged from .01 to .19 (Newcomb \& Bukowski, 1984; Terry \& Coie, 1991). The present findings, taken in conjuction with those of younger age groups, suggest that by the time children reach high school, social neglect by one's peers may be more difficult to alter than outright rejection. The socially rejected adolescent is at least noticed by others and thus can perhaps influence their perceptions. Because the neglected adolescent is socially "invisible" to his or her peers, however, this may be a more difficult obstacle to overcome.

Another interesting pattern was also apparent among the four extreme status groups; despite the relatively low stability found in three of these groups, the movement of adolescents from one social status group to another was by no means random. As Table 4 reveals, not 1 of the 43 initially rejected or neglected students moved into the more socially desirable status categories of popular or controversial during the 12 months of testing. Likewise, only 1 of the 44 initially popular or controversial students became rejected or neglected. Thus, over the course of a year, the students' social status movement was neither random nor very dramatic. Viewed in this way, the pattern of movement yet nonmovement can actually be taken as evidence of a kind of global stability in social status. Thus, it appears from this investigation that adolescents do not lose or gain social impact or social preference willy-nilly, but rather that relatively small changes in their positive and negative nominations lead them to fall into adjacent status categories or into the unclassifiable abyss. However, whereas this relatively small degree of movement might be good news for members of the higher status categories, it is unlikely to be greeted with enthusiasm by the socially disadvantaged. Indeed, this lack of movement among those within the lower social status categories provides a rather pessimistic prognosis for those who have been either negatively labeled or merely overlooked by their peers.

\section{Two Social Worlds}

Overall, our findings suggest that high school peer relations might generally be described as consisting of two distinct clusters, one made up of the popular and controversial students and the other consisting of those who are rejected and neglected. Even though these adolescents share the same physical space in high school, they appear to inhabit two very different social environments. Our description of these environments as separate social worlds is supported by two key findings. First, on virtually every measure for which a significant effect of status was found, a contrast pitting the popular-controversial groups against the rejected-neglected groups was significant. As discussed earlier, some differences were apparent between the popular and controversial groups, and at least one difference (reported grades) was apparent between the rejected and neglected students. However, for the most part these analyses support the view that higher and lower status students inhabit two separate, relatively nonoverlapping, social environments. The world inhabited by the popular and controversial students is one characterized by having more and closer friends, more intimate disclosure to these friends, more frequent social activities, and greater contact with the opposite sex. Inhabitants of this world belong to more school clubs and athletic teams and receive more social honors. Subjectively, they perceive themselves to be relatively popular and experience relatively low levels of loneliness. The other world-that inhabited by the 
rejected and neglected-is significantly less likely to possess each of these characteristics. The second source of support for the "two-worlds" argument is the finding, previously described, that virtually no status movement occurred between them during a 1-year period. Instead, the patterns of change suggested the existence of two relatively impenetrable social domains - the desirable social landscape of the popular-controversial students and the relatively undesirable terrain of those who are rejected or neglected.

If this two-worlds analogy is to have any usefulness, however, we must also account for the average and unclassifiable adolescents. How and where do they fit into this picture? In the present year-long study, popular and controversial adolescents frequently became average and unclassifiable, and vice versa. Similarly, rejected and neglected adolescents also moved into the average and unclassifiable groupings, although the rejected group did this more frequently. Thus, the average and unclassifiable realm may straddle, or at least adjoin, both worlds, serving as a non-man's-land between the extreme worlds of high and low status. This possibility is reinforced by the finding that the average group did not markedly resemble either the low- or high-status groups on a consistent basis. Because the present study involved only two observation points, we can only guess whether this adjoining social realm is a slow-moving transit point from one world to the next or simply a repository for those who stray too far beyond their world's boundaries.

The fact that there was almost no movement between these two very different worlds raises some interesting questions regarding future implications of adolescent social status. As lower status adolescents mature, will their ability to move into the higher status groups improve or deteriorate? How likely are these categories to persist into young adulthood, especially for those who are neglected in high school? Will they also be socially invisible as adults? Are the social network and subjective experiences of lower status high school students carried forward to college and the work place? Can social status even be assessed in a meaningful way outside of the structured environment-usually classrooms-typically used in this research? The results of this investigation indicate that, as in grade school, high school social status categories are indicative of important differences in social behavior and feeling states; they also begin to raise tantalizing questions about the nature of social status in contexts yet unexamined. Questions such as these are the happy result of the approach taken in this article-to explicitly combine methods and insights from contemporary developmental psychology with important concerns of social-personality psychology. Future attempts to answer these questions will, we hope, benefit both fields.

\section{Footnotes}

1 Three other studies (Davis \& Franzoi, 1986, 1991; Franzoi \& Davis, 1985) have included data from some subjects included in this investigation. All of the earlier studies had goals quite different from the present one. Two of them (Davis \& Franzoi, 1986; Franzoi \& Davis, 1985) investigated the links between private selfconsciousness, self-disclosure, and loneliness; the third (Davis \& Franzoi, 1991) examined the year-to-year stability in dispositional empathy and self-consciousness. In no case was social status examined.

$\underline{2}$ Because the internal reliability estimates for all measures in this study were virtually identical from Year 1 to Year 2, only the Year 1 figures are presented.

$\underline{3}$ Because the Year 1 status groups differed significantly in levels of physical attractiveness and differed marginally in reported grades, the possibility exists that the subsequent effects of status on social characteristics and perceptions might simply reflect the influence of these two individual characteristics. To evaluate this possibility, we carried out a series of multivariate analyses of covariance (MANCOVAs) in which we repeated the 5 (status) $\times 2$ (gender) MANOVAs - now including physical attractiveness and grades as covariates - for the five significant multivariate status effect clusters. Doing so left the original pattern of findings largely unchanged. Even though attractiveness and grades had significant covariate effects on all five clusters (all Fs $>2.50, p s<.05$ ), a significant multivariate effect of status still remained for each one. Follow-up univariate analyses were also 
largely unchanged. Only 3 of the 12 significant univariate status effects were weakened to nonsignificance in the covariance analyses: number of close friends, social honors, and perceived popularity with female students. On the other hand, after controlling for physical attractiveness and grades, two new variables - satisfaction with friendship, $F(4,180)=2.58, p<.05$, and offices held, $F(1,202)=5.68, p<.05$-exhibited significant status effects. In each case the pattern of means resembled that already described; popular and controversial students held more offices and expressed greater satisfaction than did rejected and neglected students, with average students falling in between. Because the Year 2 status groups differed significantly in family income and reported grades, we also carried out a series of MANCOVAs using income and grades as covariates. A significant multivariate effect of the income and grades covariates was found for three of the five clusters (friends and activities, disclosure and conflict, and social feelings; $F s>2.04, p s<.05)$. However, as in the original MANOVAs, four of the five MANCOVA clusters (all but the disclosure and conflict cluster) still exhibited significant multivariate status effects. For all four of these clusters, the significant univariate $F s$ were also identical to the previous analyses, except for sports involvement, which was clearly nonsignificant, $F(4,195)=1.81, p>.10$.

4 Two final concerns readers might have about the presented findings deal with potential age effects (Is the pattern of findings different for underclassmen than for upperclassmen?) and classification effects (Is the pattern of findings different using an alternative classification system for the status categories?). To examine the possibility of age effects; we conducted two other series of MANOVAs, this time including grade level (9th and 10th graders vs. 11th and 12th graders) as an additional predictor variable. As expected, age had an extremely limited effect; in both years, upperclass students were somewhat more likely than underclass students to be members in school social clubs: Year $1 F(1,200)=6.50, p<.05$; Year $2 F(1,187)=3.61, p<.06$. Most important, there was only one significant Age $\times$ Status interaction in all these analyses: opposite-sex self-disclosure in Year $2, F(4,158)=4.32, p<.01$. This interaction effect, however, was not significant in Year $1(F<1)$. Regarding the question of whether an alternative classification system would yield comparable findings, we carried out a new set of MANOVAs using the most common alternative set of criteria (Terry \& Coie, 1991)-namely classifying all available subjects by greatly expanding the size of the average category to include those who were unclassifiable in the traditional system. Analyses based on this alternative system did not differ in any meaningful way from those presently reported. In sum, then, on the basis of these two different sets of analyses, it is reasonable to conclude that the status effects reported earlier (a) were not due to a "peculiarity" in the selection criteria for status categories and (b) were similar across age groups.

\section{References}

Bukowski, W. M., \& Newcomb, A. F. (1984). Stability and determinants of sociometric status and friendship choice: A longitudinal perspective. Developmental Psychology, 20, 941-952.

Cohen, J. (1960). A coefficient of agreement for nominal scales. Educational and Psychological Measurement, 20, 37-46.

Coie, J. D., \& Dodge, K. A. (1983). Continuities and changes in children's social status: A five year longitudinal study. Merrill-Palmer Quarterly, 29, 261-282.

Coie, J. D., \& Dodge, K. A. (1988). Multiple sources of data on social behavior and social status in the school: A cross-age comparison. Child Development, 59, 815-829.

Coie, J. D., Dodge, K. A., \& Coppotelli, H. (1982). Dimensions and types of social status: A cross-age perspective. Developmental Psychology, 18, 557-570.

Coie, J. D., Dodge, K. A., \& Kupersmidt, J. B. (1990). Peer group behavior and social status. In S. R.Asher \& J. D.Coie (Eds.), Peer rejection in childhood (pp. 17-59). Cambridge, England: Cambridge University Press.

Davis, M. H., \& Franzoi, S. L. (1986). Adolescent loneliness, self-disclosure, and private self-consciousness: A longitudinal investigation. Journal of Personality and Social Psychology, 51, 595-608.

Davis, M. H., \& Franzoi, S. L. (1991). Stability and change in adolescent self-consciousness and empathy. Journal of Research in Personality, 25, 70-87.

Dodge, K. A. (1983). Behavioral antecedents of peer social status. Child Development, 54, 1386-1399. 
Dodge, K. A., Coie, J. D., \& Brakke, N. P. (1982). Behavior patterns of socially rejected and neglected preadolescents: The roles of social approach and aggression. Journal of Abnormal Child Psychology, 10, 389-409.

Evans, G. W., Palsane, M. N., Lepore, S. J., \& Martin, J. (1989). Residential density and psychological health: The mediating effects of social support. Journal of Personality and Social Psychology, 57, 994-999.

Franzoi, S. L., \& Davis, M. H. (1985). Adolescent self-disclosure and loneliness: Private self-consciousness and parental influences. Journal of Personality and Social Psychology, 48, 768-780.

French, D. D., \& Waas, G. A. (1985). Behavior problems of peer-neglected and peer-rejected elementary age children: Parent and teacher perspectives. Child Development, 56, 246-252.

Frentz, C., Gresham, F. M., \& Elliott, S. N. (1991). Popular, controversial, neglected, and rejected adolescents: Contrasts of social competence and achievement differences. Journal of School Psychology, 29, 109-120.

Jones, W. H., Carpenter, B. N., \& Quintana, D. (1985). Personality and interpersonal predictors of loneliness in two cultures. Journal of Personality and Social Psychology, 48, 1503-1511.

Kennedy, J. H. (1990). Determinants of peer social status: Contributions of physical appearance, reputation, and behavior. Journal of Youth and Adolescence, 19, 233-244.

Krebs, D., \& Adinolfi, A. A. (1975). Physical attractiveness, social relations, and personality style. Journal of Personality and Social Psychology, 31, 245-253.

Ladd, G. W. (1983). Social networks of popular, average and rejected children in school settings. Merrill-Palmer Quarterly, 29, 283-308.

Landis, J. R., \& Koch, G. G. (1977). The measurement of observer agreement for categorical data. Biometrics, 33, 159-174.

Miller, L. C., Berg, J. H., \& Archer, R. L. (1983). Openers: Individuals who elicit intimate self-disclosure. Journal of Personality and Social Psychology, 44, 1234-1244.

Newcomb, A. F., \& Bukowski, W. M. (1983). Social impact and social preference as determinants of children's peer group status. Developmental Psychology, 19, 856-867.

Newcomb, A. F., \& Bukowski, W. M. (1984). A longitudinal study of the utility of social preference and social impact sociometric classification schemes. Child Development, 55, 1434-1447.

Newcomb, A. F., Bukowski, W. M., \& Pattee, L. (1993). Children's peer relations: A meta-analytic review of popular, rejected, neglected, controversial, and average sociometric status. Psychological Bulletin, 113, 99-128.

Rosenberg, M. (1965). Society and the adolescent self-image. Princeton, NJ: Princeton University Press.

Rubin, K. H., LeMare, L. J., \& Lollis, S. (1990). Social withdrawal in childhood: Developmental pathways to peer rejection. In S. R.Asher \& J. D.Coie (Eds.), Peer rejection in childhood (pp. 217-249). Cambridge, England: Cambridge University Press.

Russell, D., Peplau, L. A., \& Cutrona, C. B. (1980). The revised UCLA Loneliness Scale: Concurrent and discriminant validity evidence. Journal of Personality and Social Psychology, 39, 472-480.

Schultz, N. R., \& Moore, D. (1984). Loneliness: Correlates, attributions, and coping among older adults. Personality and Social Psychology Bulletin, 10, 67-77.

Terry, R., \& Coie, J. D. (1991). A comparison of methods for defining sociometric status among children. Developmental Psychology, 27, 867-881.

Wills, T. A. (1991). Social support and interpersonal relationships. In M. S.Clark (Ed.), Review of Personality and Social Psychology. Prosocial behavior (Vol. 12, pp. 265-289). Newbury Park, CA: Sage. 